\title{
Phylogenetic Relationships of the Porcine Mycoplasmas Mycoplasma hyosynoviae and Mycoplasma hyopharyngis
}

\author{
WALTER A. BLANK, ${ }^{1}$ BARBARA Z. ERICKSON, ${ }^{2}$ AND GERALD W. STEMKE ${ }^{1 *}$ \\ Department of Biological Sciences, University of Alberta, Edmonton, Alberta, Canada, ${ }^{1}$ and Veterinary Medical \\ Research Institute, Iowa State University, Ames, Iowa $50011^{2}$
}

\begin{abstract}
The phylogenetic positions of the porcine mycoplasmas Mycoplasma hyosynoviae and Mycoplasma hyopharyngis were determined by using PCR-amplified $16 S$ rRNA gene sequences. $M$. hyosynoviae is a member of the Mycoplasma hominis group, while $M$. hyopharyngis belongs to the Mycoplasma fermentans group of mollicutes. Neither species is closely related to previously characterized porcine mycoplasmas belonging to the Mycoplasma hyorhinis group.
\end{abstract}

The members of the class Mollicutes that have been isolated from porcine hosts include Mycoplasma hyopneumoniae and Mycoplasma hyorhinis, both of which are considered respiratory pathogens, and Mycoplasma flocculare, a nonpathogenic respiratory organism. Mycoplasma hyopharyngis is also a respiratory isolate without obvious pathogenicity (2). In addition to these organisms, Mycoplasma hyosynoviae, which is a common inhabitant of the pharynges, tonsils, and nasal cavities, of adult pigs, has been implicated in arthritis in young pigs, which results in economic losses because of reduced growth rates (12). M. hyopneumoniae, $M$. hyorhinis, and $M$. flocculare are genetically related and, on the basis of $16 \mathrm{~S}$ rRNA sequence analysis data, belong to the $M$. hyorhinis phylogenetic group (11) along with nonporcine isolates. In this paper we describe the phylogenetic positions of $M$. hyosynoviae and $M$. hyopharyngis.

Cloning and sequencing of 16S rRNA genes. $M$. hyosynoviae S-16 (= ATCC 25591) was obtained from J. G. Tully (National Institute of Allergy and Infectious Diseases, Frederick, Md.). Cultures were grown in ATCC medium 243 supplemented with heat-inactivated pig serum, Bacto Mucin (Difco Laboratories, Detroit, Mich.), and L-arginine at $37^{\circ} \mathrm{C}$ until the medium $\mathrm{pH}$ increased from 7.0 to 7.8. DNA was isolated by gentle phenolchloroform extraction of sodium dodecyl sulfate-proteinase $\mathrm{K}$-treated cells. $M$. hyopharyngis $\mathrm{H} 3-6 \mathrm{~B} \mathrm{~F}^{\mathrm{T}}$ ( $\mathrm{T}=$ type strain) was propagated in a similar medium, which contained inactivated horse serum instead of pig serum. Each cell pellet was washed in $70 \%$ ethanol, and the resulting dried pellet was subsequently rehydrated and used directly for gene amplification. By using modified universal mollicutes primers (1) which were synthesized so that they contained $X h o I$ and $P$ stI restriction sites, the DNA was amplified to produce essentially fulllength $16 \mathrm{~S}$ ribosomal DNA copies. This amplified DNA was appropriately digested, ligated into pBluescript (Stratagene, La Jolla, Calif.), and transformed into Escherichia coli, and recombinant colonies were selected. Two $M$. hyosynoviae recombinants and one $M$. hyopharyngis $16 \mathrm{~S}$ ribosomal DNA recombinant were each grown in $500 \mathrm{ml}$ of Luria-Bertani broth, and plasmid DNA was prepared by using a Wizard Maxiprep column (Promega, Madison, Wis.). Both strands of the insertions of the plasmids were then sequenced, initially with M13 forward and reverse primers and the universal 16S rRNA

\footnotetext{
* Corresponding author. Mailing address: Department of Biological Sciences, Biological Sciences Building, University of Alberta, Edmonton, Alberta, Canada T6G 2E9. Phone: (403) 492-4430. Fax: (403) 4929234. Electronic mail address: gw_stemke@biology.ualberta.ca.
}

primers (6); then the sequences were extended by using primers from conserved sequences of mycoplasmal 16S rRNA or newly synthesized primers as needed.

Phylogenetic analysis. The sequences were analyzed at the Ribosomal Database Project (7) to find closely related bacterial species, and an unrooted tree was constructed by using the maximum-likelihood analysis method (9) at the Ribosomal Database Project and the 16S rRNA sequences of representative mollicutes (Fig. 1). A similar tree was obtained when the sequences were downloaded from GenBank, aligned by using PILEUP (Genetics Computer Group, Madison, Wis.), and subjected to a maximum-parsimony analysis with bootstrapping, using programs from the PHYLIP package (3) (data not shown).

Although $M$. hyosynoviae has been shown previously to exhibit weak cross-hybridization with an $M$. hyorhinis $16 \mathrm{~S}$ rRNAspecific probe (5), $M$. hyosynoviae is clearly a member of the Mycoplasma hominis group (8). This relationship is also reflected by the nutritional requirement of all members of the $M$. hominis group for arginine (4). Mycoplasma orale, a commonly isolated member of the human oral microflora (10), is the closest known relative of $M$. hyosynoviae. $M$. hyopharyngis belongs to neither the $M$. hyorhinis group nor the $M$. hominis group; $M$. hyopharyngis belongs to the Mycoplasma fermentans group (8), and Mycoplasma lipophilum is its closest neighbor.

Our results suggest that while coevolution could explain the relatedness of $M$. hyopneumoniae, $M$. hyorhinis, and $M$. flocculare, $M$. hyosynoviae and $M$. hyopharyngis clearly did not arise from this lineage but presumably independently colonized porcine hosts. Because the species most closely related to $M$. hyosynoviae and $M$. hyopharyngis are human commensal organisms,

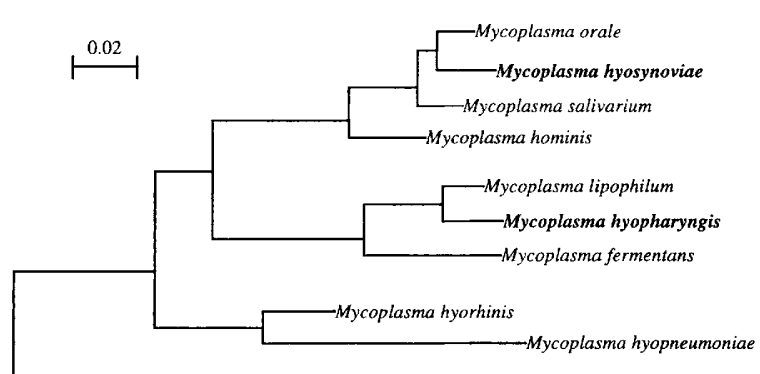

FIG. 1. Unrooted phylogenetic tree for M. hyosynoviae, M. hyopharyngis, and related species, constructed by maximum likelihood. The scale bar indicates branch lengths in units of expected nucleotide substitutions per site. 
the possibility of transmission through agricultural contact cannot be ruled out. It would be interesting to examine nondomesticated relatives of the pig to see if they are colonized by these or related mollicutes.

Nucleotide sequence accession numbers. The nucleotide sequences of $M$. hyosynoviae and $M$. hyopharyngis determined in this study have been deposited in the GenBank database under accession numbers U26730 and U58997, respectively.

We thank J. G. Tully for supplying M. hyosynoviae S-16 and J. A. Robertson for cultivation of this organism.

This work was supported by grant 0G0007320 from the Natural Sciences and Engineering Research Council of Canada.

\section{REFERENCES}

1. Deng, S., C. Huruki, J. A. Robertson, and G. W. Stemke. 1992. Detection by PCR and differentiation by restriction fragment length polymorphism of Acholeplasma, Spiroplasma, Mycoplasma, and Ureaplasma, based upon 16S rRNA genes. PCR Methods Applic. 1:202-204.

2. Erickson, B. Z., R. F. Ross, D. L. Rose, J. G. Tully, and J. M. Bove. 1986. Mycoplasma hyopharyngis, a new species from swine. Int. J. Syst. Bacteriol. 36:55-59.

3. Felsenstein, J. 1993. PHYLIP (phylogeny inference package) version 3.5c. Department of Genetics, University of Washington, Seattle.

4. Freundt, E. A. 1974. The mycoplasmas, p. 929-954. In R. E. Buchanan and N. E. Gibbons (ed.), Bergey's manual of determinative bacteriology, 8th ed. Williams and Wilkins, Baltimore.
5. Johansson, K.-E., J. G. Mattsson, K. Jacobsson, C. Fernandez, K. Bergström, G. Bölske, and P. Wallgren. 1992. Specificity of oligonucleotide probes complementary to evolutionarily variable regions of $16 \mathrm{~S}$ rRNA from Mycoplasma hyopneumoniae and Mycoplasma hyorhinis. Res. Vet. Sci. 52: 195-204.

6. Lane, D. J., B. Pace, G. J. Olsen, D. A. Stahl, M. L. Sogin, and N. R. Pace, 1985. Rapid determination of $16 \mathrm{~S}$ ribosomal RNA sequences for phylogenetic studies. Proc. Natl. Acad. Sci. USA 82:6955-6985.

7. Maidak, B. L., N. Larsen, M. J. McCaughey, R. Overbeek, G. J. Olsen, K. Fogel, J. Blandy, and C. R. Woese. 1994. The Ribosomal Database Project. Nucleic Acids Res. 22:3485-3487.

8. Maniloff, J. 1992. Phylogeny of mycoplasmas, p. 549-560. In J. Maniloff, R. N. McElhaney, L. R. Finch, and J. B. Baseman (ed.), Mycoplasmas: molecular biology and pathogenesis. American Society for Microbiology, Washington, D.C.

9. Olsen, G. J., H. Matsuda, R. Hagstrom, and R. Overbeek. 1994. fastDNAml: a tool for construction of phylogenetic trees of DNA sequences using maximum likelihood. Comput. Applic. Biosci. 10:41-48.

10. Somerson, N. L., and B. C. Cole. 1979. The mycoplasma flora of human and nonhuman primates, p. 198-200. In J. G. Tully and R. F. Whitcomb (ed.), The mycoplasmas, vol. II. Human and animal mycoplasmas. Academic Press, New York.

11. Stemke, G. W., F. Laigret, O. Grau, and J. Bove. 1992. Phylogenetic relationships of three porcine mycoplasmas, Mycoplasma hyopneumoniae, Mycoplasma flocculare, and Mycoplasma hyorhinis, and complete 16S rRNA sequence of $M$. flocculare. Int. J. Syst. Bacteriol, 42:220-225.

12. Whittlestone, P. 1979. Porcine mycoplasmas, p. 161-165. In J. G. Tully and R. F. Whitcomb (ed.), The mycoplasmas, vol. II. Human and animal mycoplasmas. Academic Press, New York. 